\title{
HUNTINGTON'S CHOREA IN THE CHINESE
}

BY

\author{
K. SINGER, M.B., M.R.C.P.Ed., D.P.M. \\ From Castle Park Hospital, Hong Kong
}

Since the original description in 1872, Huntington's chorea has been reported in many parts of the world and in different races (Wilson, 1940 ; Kishimoto, 1958). So far, however, it does not appear to have been described in the Chinese. In the past there has been a tendency to assume, without adequate data, that certain diseases are non-existent or are only of rare occurrence in the Chinese. To give an example, it was not long ago when it was claimed that syphilis was mild in the Chinese and neurosyphilis very rare (Maxwell, 1929). This led to the theory, held by some, of the "immunization" of the people through a long history of the disease (Maxwell, 1929). Such claims, like many others, are proving illusory (Wilson, 1940) in the light of advancing knowledge. Again, it is still presumed by many that multiple sclerosis is non-existent in China (M. C. Liu, 1961, personal communication). It is worthy of note, therefore, that it has recently been reported (Lin, 1961).

This paper records the occurrence of Huntington's chorea in a Chinese family of 24 members through four generations (see Diagram). Wherever possible they were examined personally. In regard to the remainder, first-hand accounts were obtained from several members and the results cross-checked.

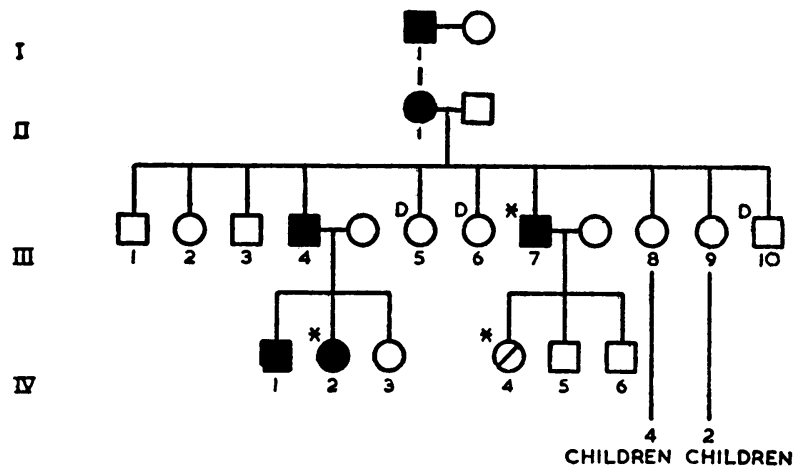

Affected male. $\boldsymbol{\theta}=$ Affected female. $\boldsymbol{O}=$ Probable early case. ${ }^{*}=$ Affected cases seen personally. $\mathrm{D}=$ Died in childhood

Two members were classical cases personally seen, and are described in some detail. One other, also seen, was a probable early case. Four more members, deceased, had been affected.

\section{Case 1}

A 40-year-old man (III 7) was first seen on account of deterioration of mental functions. His illness came on insidiously at the age of 32 . His increasing dullness, forgetfulness, frequent mistakes, and apathy finally cost him his job three years later, after which he remained unemployed. $\mathrm{He}$ also became irritable, excitable, and unduly sensitive, and on one occasion made a suicidal gesture after a tiff with his wife. At 36 he began to suffer from weakness and clumsiness of hands, and dropped objects. A year later he had weakness of legs and unsteadiness of gait. These were more severe in the morning, and on getting out of bed he often fell. He was also observed to make frequent grimaces. Later he had irregular twisting movements affecting the hands. There were occasional nodding move- ments of the head and squirming of the trunk. At 38 he began to have frequent choking at meals. The course of his illness was progressive.

On examination he was seen to be a lanky individual in fair general condition. The presenting feature was a fairly severe degree of dementia. This was shown by his tardy and laboured thinking, undefined ideation, marked poverty of thought, blunting of affect and aspontaneity. The results of performance on clinical tests for intellectual functions-for example, serial sevens, recent memory, general knowledge, word definitions-were consistent with the degree of dementia clinically evident.

In the central nervous system positive features were mainly confined to the extrapyramidal system. There were irregular jerky movements affecting mainly the face and hands. Involvement of lips, and to a lesser extent the cheeks, resulted in the grotesque expressions characteristic of chorea. Ceaseless movements of flexion-extension occurred at the interphalangeal and metacarpophalangeal joints and to a lesser extent at the wrist-joints. The movements were abrupt, irregular, fragmentary, and somewhat writhing. They were intensified by stress. They could be partially controlled by the will for short periods of time. Speech was uneven in flow. Gait was slightly lurching, the limbs tending to swing out unnecessarily. There was a moderate degree of generalized muscular wasting and weakness. Other systems, including the cardiovascular, were normal. Laboratory investigations, including serological tests of the blood and C.S.F., and plain $x$-ray films of the skull were all negative.

\section{Case 2}

A 27-year-old woman (IV 2) was seen as a result of investigations into Case 1 . She married at 20 , at which time her husband found her to be in perfectly good health and a hard-working, cheerful, and particularly able housewife.

Her illness started when she was 23 , with progressive clumsiness in holding objects. A year later spontaneous movements appeared in the hands, lips, eyelids, and the proximal parts of the upper limbs, in that order. On one occasion, against her will, she "flung" to the floor a child she happened to have in her arms. Thrice she fell down the stairs because of her clumsiness. Her speech was noticeably uneven in flow and she was unable to stop making grunting noises. Also since the onset of her illness she became increasingly inefficient, muddled in her talk, and forgetful. She herself complained of poor memory, inability to concentrate, and excitability.

On examination involuntary movements were conspicuous in the face, with pursing of lips, smirking, and screwing up of eyelids, raising of eyebrows, and other bizarre expressions. They were less frequent in the upper limbs, but all the joints were affected. There were wide excursions at the proximal joints. The movements were similar in quality to those described in Case 1. They were more widespread and severe in the present case.

Mentally she had a moderate degree of dementia. Her answers to simple questions were vague and dilatory. She showed impairment in initiative and in spontaneity and modulation of affect. A striking feature was her inability to control emotional expression, especially laughter, and this was, in fact, one of her complaints.

Clinical tests for intellectual function, as in Case 1, also demonstrated her deterioration. The other systems were normal. Plain $x$-ray films of the skull and serological tests for syphilis among other investigations were negative.

\section{Case 3}

A 14-year-old girl (IV 4) had since the age of 10 become excessively clumsy and dropped objects. She had also become progressively dull and her position in class deteriorated from above average to near the bottom. 
On examination the only positive but unequivocal finding was tremor and incoordination of the arm on performance of the finger-nose test. It appears probable that she had Huntington's chorea in its early stage.

The following are brief notes on the deceased members who were affected.

I 1.- Onset of illness occurred in middle age and death at 65 . He suffered from old jerky movements of the limbs and progressively became "very stupid."

II 1.- Onset of illness occurred at about 40 and she died at 50. She had involuntary jerky twisting movements affecting the hands, face, head, limbs, and trunk. She "flung" out her limbs at times, both at rest and when walking. Her mental functions also declined and she became slow in speech and poor in memory. During the last year of illness she was weak and bedridden and had to be spoon-fed.

III 4.- Onset of illness occurred at 29 and he died at 37. The sequence of events was clumsiness in grasp; spontaneous loose abrupt movements affecting all limbs; and progressive generalized weakness. Mental faculties, however, were preserved to the end.

IV 1.- Onset was at 22 and death occurred at 28 . Here also the illness started with clumsiness followed by involuntary movements similar to those in the preceding cases and affecting most parts of the body. Articulation became severely defective. He was demented for the last two years.

\section{Comment}

In this family there were seven cases (including one probable case) of Huntington's chorea. Four were males and three females. The age at onset ranged from 10 years to middle age. The two cases described in detail had chorea and dementia in degrees varying from moderate to severe. Chorea and dementia were also present in all the other affected members of the family, with the exception of one (III 4) in whom intellectual functions were preserved to the end.

The heredo-familial character of the disease and its Mendelian dominant inheritance are evident. The four choreic parents in the family had 17 siblings between them. Six were affected--that is, about one-third. Of the rest, eight were well (including two below the age of 10) and three died in childhood.

I am indebted to the Honorary Director of Medical and Health Services, Hong Kong, for permission to publish this paper.

\section{REFERENCES}

Huntington, G. (1872). Med. Surg. Reporter, 26, 317.

Kishimoto, K. (1958). Third International Congress of Neuropathology, Brussels, 1957. Amsterdam Excerpta Medica Foundation

Lin, T. Y (1961). Amer. J. Psychiat., 117, 966

Maxwell, J. L. (1929) Diseases of China, 2nd ed. Shanghai. Wilson, S. A. K. (1940). Neurology. Arnold, London.

Sir William Fletcher Shaw, of Manchester, Emeritus Professor of Obstetrics and Gynaecology at Manchester University, President of the Royal College of Obstetricians and Gynaecologists, 1938, left $£ 46,569$ gross, $£ 46,058$ net (duty paid, £13,742). He left $£ 1,000$ and the George II silver salver presented to him by the past and present members of the council of the college "and also the gold medal awarded to me for my M.D. thesis" to the Royal College of Obstetricians and Gynaecologists, and $£ 300$ to the Rector and Churchwardens of Swettenham Church, Cheshire. upon trust to apply the income towards the maintenance and repair of the communion table, the choir stalls, memorial tablet, oak panelling, and pavement. (The Times, April 13.)
ACUTE TRANSIENT ARTHRITIS OF THE ADULT HIP

\section{ITS RELATION TO RHEUMATOID ARTHRITIS} AND TO "PALINDROMIC RHEUMATISM"

BY

\author{
RONALD LASS, M.R.C.P. \\ Consultant Physician
}

AND

EDMUND SHEPHARD, F.R.C.S. Consultant Orthopaedic Surgeon

West Kent General Hospital, Maidstone

During a period of four years we have seen eight adult patients with an acute arthritis of the hip, accompanied by intense and disabling pain, which resolved, leaving the joint more or less normal. Aspiration was performed on seven of them; cloudy yellow fluid under pressure was obtained in five and proved sterile in each. This paper presents the clinical and laboratory findings, follow-up observations, and probable diagnosis in these eight patients.

Case 1

A woman aged 68 had for 12 years been subject to occasional attacks of pain and swelling in the hands, wrists, knees, and ankles. She presented with severe pain of sudden onset in the right hip, accompanied by vomiting. The right hip-joint was tender and its movement restricted and painful. Temperature $100^{\circ}$ F. $\left(37.8^{\circ} \mathrm{C}\right.$.) ; white blood-cell count (W.B.C.), 4,000/c.mm. (differential count normal); erythrocyte sedimentation rate (E.S.R.), $54 \mathrm{~mm} . / 1$ hour (Westergren). The Rose-Waaler test (Rose et al., 1948) was positive at $1 / 256$.

Aspiration of the right hip-joint yielded $10 \mathrm{ml}$. of cloudy yellow fluid. Penicillin 250.000 units was introduced into the joint and systemic penicillin given. The aspirated fluid showed numerous polymorphonuclear leucocytes and no organisms. Culture was sterile. Severe pain subsided in three days and full function returned in four weeks.

Four and a half years later there had been no further pain in the right hip, which had full painless movement. The hands showed rheumatoid changes. E.S.R., $22 \mathrm{~mm}$./ 1 hour. Latex test (Singer and Plotz, 1956) was positive at $1 / 160$.

\section{Case 2}

A man aged 43 presented with severe pain of recent onset in the right hip. The joint was immobilized by muscle spasm. By next morning the left hip and both ankles were affected. Temperature $99^{\circ}$ F. $\left(37.2^{\circ}\right.$ C.) ; E.S.R., 43 rising to $82 \mathrm{~mm}$./ 1 hour ; W.B.C., $14,600 /$ c.mm. (neutrophils $79 \%$, eosinophils $1 \%$, monocytes $8 \%$, lymphocytes $12 \%$ ). Aspiration was not performed. Treatment consisted of bed rest, sodium salicylate for two weeks, and chloroquine $400 \mathrm{mg}$. daily for five weeks. Severe pain subsided after two days, and at two weeks all pain had gone.

Twenty-seven months after onset there was occasional slight ache in the right buttock and thigh. Both hips had full painless movement. E.S.R., $1 \mathrm{~mm} . / 1$ hour. Latex test was negative throughout.

\section{Case 3}

A man aged 52 presented with right hip pain. Two weeks previously severe pain and "fixation" of the right hip had necessitated admission to another hospital. There had been no urethritis but there had been recurrent conjunctivitis complicated by superficial punctate keratitis. The right hip-joint was slightly tender. Flexion was from 10 degrees to full, rotation was very restricted and abduction slightly 